\title{
ASSOCIATIONS BETWEEN THE UPPER EXTREMITY FUNCTION AND COGNITION IN POST-STROKE PATIENTS
}

DOI: 10.36740/WLek202108124

\author{
Iriah F. Uwa-Agbonikhena, Viktoriia A. Gryb, Viktoriia R. Gerasymchuk \\ IVANO-FRANKIVSK NATIONAL MEDICAL UNIVERSITY, IVANO-FRANKIVSK, UKRAINE
}

\begin{abstract}
The aim: Was to determine the relations between the the upper extremity function and cognition in post-stroke patients.

Materials and methods: Totally there were 86 patients examined in the 1-year period after first-ever anterior circulation ischemic stroke. Examination of the upper extremity function was performed with the Fugl-Meyer assessment (FMA). Cognitive function was assessed with the Mini Mental State Examination (MMSE), Montreal Cognitive Assessment (MoCA), Frontal Assessment Battery (FAB), Trail-making Test A and B (TMT) and the Clock Drawing Test (CDT).

Results: Motor dysfunction mostly manifested in low "Wrist" and "Hand" subtests scores (5 and 7, respectively) and therefore resulted in decreased "Total motor function" score of 40 . The most significant relations were found out between the FMA "Hand", "Total motor function" subtests and Cl indices. MoCA score correlated with FMA "Wrist" ( $r=0.34$; $p=0.021)$, "Hand" $(r=0.52 ; p=0.001)$ and "Total motor function" $(r=0.48 ; p=0.003)$ scores. "Hand" score also correlated with the $F A B(r=0.43 ; p=0.012), C D T(r=0.22 ; p=0.016)$, TMT-A $(r=-0.31 ; p=0.023)$ and TMT- $B(-0.48 ; p=0.009)$ scores. There was no significant correlation between the sensory FMA subtests.

Conclusion: Our findings suggest that upper extremity motor impairment, especially hand and wrist dysfunction, are associated with cognitive impairment and executive functions disorder in particular.
\end{abstract}

KEY WORDS: cognitive impairment, stroke, upper extremity function

Wiad Lek. 2021;74(8):1917-1920

\section{INTRODUCTION}

Stroke remains one of the major causes of disability nowadays. A significant decrease in stroke mortality within the recent decades and its constantly high incidence are contributing to an increasing number of disabled stroke survivors [1]. The most active and effective recovery takes place within the first 3 months after stroke [2]. However, rehabilitation of post-stroke patients in later periods becomes even more important due to delay or ineffectivity of the early rehabilitation.

Motor and cognitive dysfunction are the most prevalent among the stroke consequences and have a high impact on the patients' life quality $[3,4]$. These syndromes are usually studied and treated as distinct entities, though both of them may influence each other's course and manifestations. It is known that cognitive impairment (CI) and especially dementia decrease the effectivity of motor rehabilitation [5]. However, there is an emerging evidence that motor dysfunction may also contribute to occurrence of $\mathrm{CI}$ and its progression. It was reported that the gait speed and grip strength may be risk factors of cognitive decline in elderly patients [6]. Manual dexterity and fine motor skills are considered one of the most important predictors influencing the further $\mathrm{CI}$ in patients with cardiovascular diseases $[7,8]$. Detailed study of these associations in post-stroke patients may be helpful in development of the rehabilitation strategies which could influence both cognition and motor function and be the most beneficial for patients' recovery.

\section{THE AIM}

The aim of study was to determine the relations between the motor and sensory parameters of the upper extremity function and cognition in patients 1 year after ischemic stroke.

\section{MATERIALS AND METHODS}

The study was performed in the department of neurology and neurosurgery of Ivano-Frankivsk National Medical University and the vascular neurology department of Ivano-Frankivsk Regional Hospital in 2018-2020. All patients signed an informed consent before involvement into the study. Totally there were 86 patients ( 51 males, 34 females; mean age $64[55 ; 74]$ years) examined in the 1 -year period after first-ever anterior circulation ischemic stroke. Stroke was localized in the left cerebral hemisphere in 41 (47.7\%) patients and in the right hemisphere in 45 (52.3\%) patients.

Exclusion criteria:

1. hemorrhagic stroke;

2. recurrent stroke;

3. posterior circulation stroke;

4. age $<50$ and $>80$;

5. left-handed patients;

6. period of $<12$ month and $>24$ month after stroke;

7. plegia or severe paresis of the upper extremity;

8. sensory or severe motor aphasia;

9. malignancy and systemic comorbidities; 
Table I. Parameters of the upper extremity function in post-stroke patients, Me [Q25\%; 075\%]

\begin{tabular}{cc}
\hline FMA parameter (range) & Score \\
\hline Upper extremity $(0-36)$ & $24[18 ; 32]$ \\
\hline Wrist $(0-10)$ & $5[2 ; 7]$ \\
\hline Hand $(0-14)$ & $7[3 ; 9]$ \\
\hline Speed / coordination $(0-6)$ & $4[3 ; 5]$ \\
\hline Total motor function $(0-66)$ & $40[26 ; 53]$ \\
\hline Sensation $(0-12)$ & $8[5 ; 10]$ \\
\hline Passive joint movement $(0-24)$ & $14[10 ; 20]$ \\
\hline Joint pain $(0-24)$ & $18[16 ; 21]$
\end{tabular}

Table II. Parameters of cognitive function in post-stroke patients, Me [Q25\%; Q75\%]

\begin{tabular}{cc}
\hline Parameter (range) & Score \\
\hline MMSE $(0-30)$ & $24[20 ; 26]$ \\
\hline MoCA $(0-30)$ & $23[17 ; 25]$ \\
\hline FAB $(0-18)$ & $13[12 ; 15]$ \\
\hline CDT $(0-10)$ & $7[5 ; 8]$ \\
\hline TMT-A (sec) & $56[43 ; 71]$ \\
\hline TMT-B $(\mathrm{sec})$ & $142[122 ; 175]$
\end{tabular}

10. severe depression (Hospital Anxiety and Depression Scale (HADS) score $>11$ );

11. previous disability (orthopedic etc).

Examination of the upper extremity function was performed with the Fugl-Meyer assessment (FMA) (Fugl-Meyer AR et al., 1975). Cognitive function was assessed with the Mini Mental State Examination (MMSE), Montreal Cognitive Assessment (MoCA), Frontal Assessment Battery (FAB), Trail-making Test A and B (TMT) and the Clock Drawing Test (CDT). Screening for depression was performed with the help of HADS scale; pre-existing $\mathrm{CI}$ was excluded with the IQ-code questionnaire.

Statistical analysis of the results was carried out with the help of statistical data analysis software "Statistica 6.0" and "MS Excel" using nonparametric evaluation methods. Data are shown as Median (Me) and interquartile interval [Q25\%; Q75\%]. Correlation between the parameters was estimated with the Spearman's rank correlation coefficient. Statistical significance was defined as $\mathrm{p}$-value $<0.05$.

\section{RESULTS}

Examination of patients' upper extremity function with the FMA detected motor dysfunction, which mostly manifested in low "Wrist" and "Hand" subtests scores (5 $[2 ; 7]$ and $7[3 ; 9]$, respectively) and therefore resulted in decreased "Total motor function" score of $40[26 ; 53]$ out of 66 maximally possible (Table I). Evaluation of cognitive functions determined decreased total MMSE, MoCA, FAB and CDT tests score compared to cut-off levels, and increase of TMT-A and TMT-B performance time (Table II).
Table III. Correlations between the motor and cognitive function parameters in post-stroke patients

\begin{tabular}{|c|c|c|}
\hline FMA parameter & $\mathbf{r}$ & p-value \\
\hline \multicolumn{3}{|c|}{ MMSE } \\
\hline Upper extremity & 0.21 & 0.166 \\
\hline Wrist & 0.38 & 0.093 \\
\hline Hand & 0.27 & 0.081 \\
\hline Speed / coordination & 0.12 & 0.219 \\
\hline Total motor function & $0.29 *$ & 0.026 \\
\hline Sensation & 0.21 & 0.587 \\
\hline Passive joint movement & 0.09 & 0.245 \\
\hline Joint pain & 0.15 & 0.421 \\
\hline \multicolumn{3}{|c|}{ MoCA } \\
\hline Upper extremity & 0.19 & 0.097 \\
\hline Wrist & $0.34^{*}$ & 0.021 \\
\hline Hand & $0.52^{*}$ & 0.001 \\
\hline Speed / coordination & 0.34 & 0.068 \\
\hline Total motor function & $0.48^{*}$ & 0.003 \\
\hline Sensation & 0.16 & 0.159 \\
\hline Passive joint movement & 0.08 & 0.328 \\
\hline Joint pain & 0.14 & 0.166 \\
\hline \multicolumn{3}{|c|}{ FAB } \\
\hline Upper extremity & 0.19 & 0.116 \\
\hline Wrist & 0.38 & 0.073 \\
\hline Hand & $0.43^{*}$ & 0.012 \\
\hline Speed / coordination & 0.23 & 0.089 \\
\hline Total motor function & $0.44^{*}$ & 0.009 \\
\hline Sensation & 0.09 & 0.216 \\
\hline Passive joint movement & 0.15 & 0.302 \\
\hline Joint pain & 0.11 & 0.124 \\
\hline \multicolumn{3}{|c|}{ CDT } \\
\hline Upper extremity & 0.08 & 0.746 \\
\hline Wrist & 0.11 & 0.183 \\
\hline Hand & $0.22^{*}$ & 0.016 \\
\hline Speed / coordination & 0.29 & 0.053 \\
\hline Total motor function & $0.26^{*}$ & 0.034 \\
\hline Sensation & 0.32 & 0.182 \\
\hline Passive joint movement & 0.14 & 0.351 \\
\hline Joint pain & 0.06 & 0.224 \\
\hline \multicolumn{3}{|c|}{ TMT-A } \\
\hline Upper extremity & -0.36 & 0.128 \\
\hline Wrist & -0.41 & 0.073 \\
\hline Hand & $-0.31^{*}$ & 0.023 \\
\hline Speed / coordination & -0.18 & 0.096 \\
\hline Total motor function & -0.39 & 0.074 \\
\hline Sensation & -0.27 & 0.528 \\
\hline Passive joint movement & -0.09 & 0.269 \\
\hline Joint pain & -0.11 & 0.134 \\
\hline \multicolumn{3}{|c|}{ TMT-B } \\
\hline Upper extremity & -0.23 & 0.059 \\
\hline Wrist & $-0.31^{*}$ & 0.026 \\
\hline Hand & $-0.48^{*}$ & 0.009 \\
\hline Speed / coordination & $-0.22^{*}$ & 0.047 \\
\hline Total motor function & $-0.41^{*}$ & 0.012 \\
\hline Sensation & -0.18 & 0.236 \\
\hline Passive joint movement & -0.11 & 0.188 \\
\hline Joint pain & -0.13 & 0.365 \\
\hline
\end{tabular}

Note: * significance of correlation. 
The most significant relations were found out between the FMA "Hand", "Total motor function" subtests and CI indices (Table III). MoCA score correlated with FMA "Wrist" ( $\mathrm{r}=0.34 ; \mathrm{p}=0.021)$, "Hand" $(\mathrm{r}=0.52 ; \mathrm{p}=0.001)$ and "Total motor function" ( $\mathrm{r}=0.48 ; \mathrm{p}=0.003)$ scores. "Total motor function" score also correlated with the MMSE $(r=0.29 ; p=0.026)$, FAB $(r=0.44 ; p=0.09)$, CDT $(r=0.026$; $\mathrm{p}=0.034)$ and TMT-B $(\mathrm{r}=-0.41 ; \mathrm{p}=0.012)$ scores. "Hand" score also correlated with the FAB $(r=0.43 ; \mathrm{p}=0.012)$, CDT $(\mathrm{r}=0.22 ; \mathrm{p}=0.016)$, TMT-A $(\mathrm{r}=-0.31 ; \mathrm{p}=0.023)$ and TMT-B $(-0.48 ; \mathrm{p}=0.009)$ scores.

There was no significant correlation between the FMA subtests "Sensation", "Passive joint movement", "Joint pain" and CI manifestations in examined patients.

\section{DISCUSSION}

Interactions between cognitive and motor impairment became a subject of great interest within the last years. Prevalence of post-stroke CI is high and varies from 19 to $92 \%$, depending on severity and the method used for its detection [3,4]. Upper extremity motor impairment is a leading factor that impacts long-term disability due to a major role of manual dexterity in patients' self-care and functional independence.

McGrath R. et al. [7] reported that handgrip weakness and asymmetry are associated with CI. Similar data were obtained in the elderly population [6] and cardiovascular patients' cohort [8]; these findings consider hand motor dysfunction a probable predictor of further cognitive decline. Presence of hand motor impairment was also associated with worse cognitive performance in patients with mild CI and dementia [9].

In our study the most significant correlations were observed between the arm motor functioning and cognitive scales which include examination of the executive functions (TMT $A$ and $B, F A B, M o C A$ ), while traditionally used MMSE didn't show so much significance. Fine motor skills impairment, which resulted in decreased FMA "Hand" "Wrist" and "Total motor function" scores also appeared to be the most important risk factor of CI; upper arm functioning score didn't correlate with cognition in examined patients. There was also no evidence of sensory dysfunction influence on CI manifestations.

These findings may be explained by the role of the frontal lobe in providing of both executive functions and motor control, which is the underlying basis for coexistence and close interactions between cognition and fine motor skills [10]. It may also provide a pathogenetical support for use of rehabilitation activities which target fine motor skills and manual dexterity improvement and may also contribute to cognition. There is similar evidence about the favorable influence of general physical activity on cognitive functioning of patients with mild CI and dementia [11]. Although benefits of general physical activity for poststroke patients have also been reported [12], they have not focused on precise evaluation and improvement of hand motor function. That is why further studies of this problem are relevant and may create a wide prospective post-stroke patients' rehabilitation, functional independence and life quality improvement.

\section{CONCLUSIONS}

Our findings suggest that upper extremity motor impairment, especially hand and wrist dysfunction, are associated with cognitive impairment and executive functions disorder in particular. Further research is needed in regard to the prognostic significance of these findings and their impact on the treatment and rehabilitation strategies.

\section{REFERENCES}

1. Krishnamurthi R.V., Moran A.E., Feigin V.L. et al. Stroke prevalence, mortality and disability-adjusted life years in adults aged 20-64 years in 1990-2013: data from the global burden of disease 2013 study. Neuroepidemiology. 2015; 45: 190 - 202.

2. Hara Y. Brain plasticity and rehabilitation in stroke patients. Journal of Nippon Medical School. 2015; 82 (1): 4 - 12.

3. Coco D., Lopez G., Corrao S. Cognitive impairment and stroke in elderly patients. Vascular Health and Risk Management. 2016; 12: 101 - 105.

4. Brainin M., Tuomilehto J., Heiss W.D. et al. Post-stroke cognitive decline: an update and pespectives for clinical research. European Journal of Neurology. 2015; 22: 229- 238.

5. Mullick A.A., Subramanian S., Levin M.F. Emerging evidence of the association between cognitive deficits and arm motor recovery after stroke: a meta-analysis. Restorative Neurology and Neuroscience. 2015; 33 (3): 389 - 403. doi: 10.3233/RNN-150510.

6. Ruan Y., Shi Y., Guo Y.F. et al. Association between grip strength, rapid gait speed and cognition in people aged 50 and above in Shanghai during 2009-2010. 2020; 54 (12):1414-1420. (Chinese) doi: 10.3760/ cma.j.cn112150-20200714-01003.

7. McGrath R., Cawthon P.M., Cesari M. et al. Handgrip Strength Asymmetry and Weakness AreAssociated with Lower Cognitive Function:APanel Study.Journal of the American Geriatric Society.2020;68(9):2051-2058. doi:10.1111/jgs. 16556.

8. Ishihara K., Izawa K.P., Kitamura M. Pinch strength is associated with the prevalence of mild cognitiveimpairmentin patients with cardiovasculardisease. Journal of Cardiology. 2020;75(6):594-599. doi: 10.1016/j.jcc.2019.12.009.

9. Hesseberg K., Tangen G.G., Pripp A.H. et al. Associations between Cognition and Hand Function in Older People Diagnosed with Mild Cognitive Impairment or Dementia. Dement Geriatr Cogn Disord Extra. 2020;1 0:195-204. doi: 0.1159/000510382.

10. Leisman G, Moustafa AA and Shafir T. Thinking, Walking, Talking: Integratory Motor and Cognitive Brain Function. Front. Public Health 2016; 4: 94. doi: 10.3389/fpubh.2016.00094.

11. Law C.K., Lam F.M., Chung R.C. et al. Physical exercise attenuates cognitive decline and reduces behavioural problems in people with mild cognitive impairment and dementia: a systematic review. Journal of Physiotherapy. 2020; 6 (1): 9-18. doi:10.1016/j.jphys.2019.11.014.

12. Han P., Zhang W., Kang L. etal. Clinical Evidence of Exercise Benefits for Stroke. AdvExp Med Biol.2017;1000:131-151.doi: 10.1007/978-981-10-4304-8_9.

This study is a part of the complex scientific research of the neurology and neurosurgery department "Clinical and pathogenetical aspects of diagnostics and treatment of the diseases of nervous system and metabolism", registration number 0115U007142, 2015-2019.

\section{ORCID and contributionship:}

Iriah F. Uwa-Agbonikhena: 0000-0002-2914-1523 ${ }^{A, B, C, D}$

Viktoriia A. Gryb: 0000-0001-6111-7921 A,E,F

Viktoriia R. Gerasymchuk: 0000-0001-8481-8253 A,C,D 


\section{CORRESPONDING AUTHOR}

Viktoriia R. Gerasymchuk

Ivano-Frankivsk National Medical University

2 Halytska St.. 76018 Ivano-Frankivsk, Ukraine

tel: +380959096394

e-mail:viktorianeuro@gmail.com

Received: 28.04 .2021

Accepted: 30.07 .2021

A - Work concept and design, B - Data collection and analysis, C - Responsibility for statistical analysis,

D-Writing the article, $\mathbf{E}$-Critical review, $\mathbf{F}$ - Final approval of the article 